\title{
Methodological proposal for occupational health and safety actions in research laboratories with nanotechnologies activities
}

\author{
Luís Renato Balbão Andrade ${ }^{\mathrm{a}}$ and Fernando Gonçalves Amaral ${ }^{\mathrm{b}}$ \\ ${ }^{a}$ FUNDACENTRO - Employment and Working Ministry, Av.Borges de Medeiros, 659/10 andar, CEP 90020-023, \\ Porto Alegre, Rio Grande do Sul, Brazil \\ ${ }^{b}$ Production Engineering and Transportation Department, Federal University of Rio Grande do Sul, Av. Osvaldo \\ Aranha 99, $5^{\circ}$ floor, CEP 90035-190, Porto Alegre, RS, Brazil
}

\begin{abstract}
Nanotechnologies is a multidisciplinary set of techniques to manipulate matter on nanoscale level, more precisely particles below $100 \mathrm{~nm}$ whose characteristic due to small size is essentially different from those found in macro form materials. Regarding to these new properties of the materials there are knowledge gaps about the effects of these particles on human organism and the environment. Although it still being considered emerging technology it is growing increasingly fast as well as the number of products using nanotechnologies in some production level and so the number of researchers involved with the subject. Given this scenario and based on literature related, a comprehensive methodology for health and safety at work for researching laboratories with activities in nanotechnologies was developed, based on ILO structure guidelines for safety and health at work system on which a number of nanospecific recommendations were added to. The work intends to offer food for thought on controlling risks associated to nanotechnologies.
\end{abstract}

Keywords: nanotechnologies, OHS, health, laboratories

\section{Introduction}

Nanotechnologies are characterized by two main aspects: the first refers to the size scale, which should be below 100 nanometers, the second relates to the fact that nanoscale should lend the material new features not found on larger scale materials. These new features present many uncertainties about safety, health and environment. Management systems literature is plentiful. Barry [4] reports that there is no convergence between different authors on how to design, implement and maintain an OHS (Occupational Health and Safety) management system, in other words, by corollary they do not indicate which one would be the best model to be applied on this implementation. The same author however identifies that various models are converging* on the fact that organization should incorporate an OSH policy, carrying out a plan that allows action plans definition, enabling the implementation of this planning and performing a checking and corrective actions on the actions which may have deviations from what was originally planned and finally, do not stop promoting critical analysis of the system operation effectiveness. In terms of management systems related to safety and health or occupational health and safety (OHS) two documents stand out: the management system OHSAS 18.001/2007 (Occupational Health and Safety Assessment Series) [1, 2] and the system OHS/2001 ILO (International Labour Organization) [9]. Both

\footnotetext{
* Corresponding author: E-mail: luis.andrade@fundacentro.gov.br
} 
documents include the elements highlighted by Barry [4].

A quick analysis of these systems (OHSAS 18001 and ILO) shows that they do not differ in their essence [1] although they have some differences, among which three of them stand out.

1) The focus: the system advocated by ILO focuses on workers (labors) while the OHSAS system focuses on the organization (capital). This is probably the biggest difference between both systems since the other two derive from them.

2) "Responsibility and Accountability" contained in ILO guidelines are not covered in OHSAS system.

3) "Competence and training" as ILO guidelines recommend that "it is appropriate to provide training at no cost to all participants and that it should be made if possible during working hours". OHSAS system has no explicit requirements in this regard.

Considering this scenario, timid actions are still undertaken in order to understand the enormity of nanotechnologies impact on working world. Given the existing tools, this work aims to develop a methodology to structure and evaluate safety and health at work actions in research laboratories with nanotechnologies activities based on ILO OHS/2001 [9] key elements taking into account that its focus is primarily the workers.

\section{Methodology}

For this proposal, some management systems main features as [4], ILO (2001) [9] and OHSAS 18001 [1.2], nanospecific management systems like "The NanoRisk Framework" [5] and Controlbanding Nanotool [10] regulations OHS nanoespecifics (when available) were analyzed as well as existing standards for laboratories with activities in nanotechnology such as Massachusetts Institute of Technology [11] Texas A\& M Engineering [14] and U.S. Stanford Linear Accelerator Center [16].

Also it was developed through compilation of the above documents in order to be more inclusive and attend each and every one of them. The proposed algorithm incorporates a risk rating in three levels so that more stringent control measures could be adopted depending on the potential risk to be controlled. Adapted from Fronza, Guterres, Pohlmann and Teixeira
[7].

In order to be validated the proposal was submitted to three expert groups: (1) OSH specialists, (2) nanotechnology experts (3) OHS nanotechnologies knowledge specialists.

\section{Results}

The application procedures for workers safety and health and the environment preservation is the risk perception even though it is not restricted only to it (National Institute for Occupational Safety and Health [17].

The uncertainty about nanoparticles effects on human body seems to help put the concern about potential risks of these particles in the background [15]. You may notice remarks on that a particular element or procedure is safe even if they are new and have not been tested in this regard yet. In addition, standards and statutes may be viewed as obstacles to scientific development and not as a protection way. The methodology developed offers thoughts on the use of nanotechnologies so that it can mitigate safety and health risks of those who work with them in research laboratories. This methodology is based on ILO document [9] which incorporates the precautionary principle. Its main elements can be identified in Figure 1. Also the same figure indicates the continuity character of actions or continuous cycle in order to work systemically meaning each of the actions depending on and influencing the others. The methodology in question incorporates a classification algorithm (Figure 2) of activities based on the intrinsic hazard of nanoparticles and the frequency that they are handled allowing a qualitative assessment of risk level involved in dealing with these nanoparticles. The algorithm in Figure 2 allows the classification of activities involving nanoparticles into three distinct groups regarding the risk, being the group I considered less dangerous than the group III. Other activities are classified in the methodology description itself, and existing more than one possible classification for the same activity or nanomaterial the highest risk measures is recommended. Although the general principle and major of the methodology should be applied regardless the specific group there are some more or less stringent actions related to the possibility of contamination 
linked to the risk group.

\subsection{Definition}

Nanoparticle or nanomaterial: any particle that has 2 or 3 of its dimensions below 100 nanometers. Groups rating: the methodology proposal indicates that activities involving nanomaterials should be classified in groups through flowchart shown in Figure 2.

\subsection{Application Field}

Research laboratories manipulating nanoparticles.

\subsection{Precautionary principle}

In all activities involving nanomaterials the precautionary principle should be adopted where these nanomaterials should be considered potentially dangerous and be treated as such until there is real evidence that they are harmless.

\subsection{Methodology description}

1. Policy

1.1 Policy establishment

1.1.1 Develop a written OSH policy with everyone involved participation

1.1.2 The policy developed must be endorsed by the leaders, be clear and concise, be accessible to internal and external public (transparency) and finally be reviewed periodically.

1.2. Participation of everyone involved

1.2.1 At all stages of the process (design, implementation, execution, evaluation and adjustment) it is extremely important the personnel involved participation including those on supporting activities such as cleaning, for example.

2. Organization

2.1 Responsibility and accountability

2.1.1 OHS is the personnel directors responsibility and everyone must be aware of it as well as resources allocation to implement this policy.

2.1.2 Accountability for OHS actions is part of the basic rights to information and may be provided by the management.
2.2 Competence and qualification

2.2.1 Everyone involved should be qualified within their area of expertise regarding to OHS.

2.2.1.1 Laboratories in Group III (red): OHS training must be updated annually.

2.3 Documentation

2.3.1 OHS management system should be followed by extensive documentation.

2.3.2 Documentation should include at least: (a) the OHS policy, (b) the roles and responsibilities of those involved, (c) the risk factors, (d) plans, procedures and instructions of the OHS system, such as safety planning, chemical hygiene plan, standard operating procedures and safety material data sheets; (e) track record such as incidents, accidents, injuries, health deterioration, exposure to risk agents, environmental monitoring and medical surveillance.

2.4 Communication

2.4.1 Information flow must be guaranteed in order to receive, document and answer OHS questions, opinions and suggestions from both internal at all levels as the general public.

3. Planning and implementation

3.1 Technical measures to prevent and control risks

3.1.1 The measures in general should be adopted in the following priority order: elimination, reduction, control and personal protective equipment surveillance.

3.1.2 Replacement: whenever possible - technically possible and economically acceptable nanopowders should be replaced by forms in dispersions, pastes, compounds/composites and dispersion in liquid or solid.

3.1.2.1 Using nanopowders frequently: group III (red)

3.1.2.2 Using nanopowders sporadically: group II (orange)

3.1.2.3 Not using nanopowders: group I (yellow)

3.1.3 Nanomaterials handling should be conducted in closed systems with negative pressure relative to the breathing zone of the person involved in the process.

3.1.3.1 Group III (red): closed system as of biological safety, glove boxes or similar.

3.1.3.2 Group II (orange): laminar flow with HEPA filters (High Efficiency ParticulateAir).

3.1.3.3 Group I (yellow): laminar flow or recirculation with HEPA filtration. 
3.1.4 Ventilation and filtration are recommended for all groups. Nanomaterials should be used for HEPA filters and depression of stable $6 \mathrm{~mm}$ of water must be kept in the laboratory where there can be no recirculation of ventilation. It is recommended 6 to 12 air changes per hour; HEPA filtration should be done to exhaust air out in the case of Group III (Red) [6].

3.1.5 Special attention should be given to fire or explosion possibility caused by nanoparticles. If necessary, electrical systems explosion proof and alarm systems should be used.

3.1.6 Laboratories should be equipped with eye wash station, safety shower, first aid kit, fire extinguisher suitable and properly marked emergency exits.

3.2 Organizational measures to prevent and control risks

3.2.1 Access control: the areas where nanomaterials are handled should have strict access controlled in order to minimize exposition.

3.2.1.1 Group III (red): electronic control may be adopted. 3.2.1.2 Group II (orange): controlled access through documentation.

3.2.1.3 Group I (yellow): controlled access by warnings and internal rules.

3.2.2 Risk activities performed out of normal working hours should not be allowed to avoid the execution by just one person. Risk activities should always be performed in the presence of at least two people.

3.2.1.1 Group III (red): will not be allowed to perform out of regular working hours.

3.2.1.2 Group II (orange): may performed by at least 2 people

3.2.1.3 Group I (yellow): will be allowed to perform after regular working hours by a single person since there is a prior and accepted communication.

3.2.3 In nanomaterials working areas, eating, drinking, smoking or chewing gums should not be allowed also these areas may not be used for storage of food or cosmetics. By the same principle nanoparticles storage must not occur in such diverse areas as hallways, offices and others. Specific areas for these purposes should be designed.

3.2.4 It is suggested to identify the need or not, in providing laundry services to people who work with nanomaterials in order to prevent them from taking home contaminated clothing. In this case the workplace will eventually provide changing rooms and bathing.

3.2.4.1 Laboratories in Group III (red): laundry service must be provided.

3.2.5 Changes management: new equipment and procedures should only be adopted after a careful analysis of their impacts on OHS.

3.3 Labeling

3.3.1 All nanomaterial should be properly labeled providing information about possible adverse reactions and special care in manipulating.

3.3.2 Areas with nanomaterials presence should be flagged and indicate specific controlling procedures and protective equipment that should be adopted. 3.3.3 All nanomaterials must be categorized by the hazard flowchart and labeled as such using the colors red (group III), orange (group II) and yellow (group I).

3.4 Cleaning

3.4.1 Cleaning procedures must be properly described and have qualified personnel for safe performance of these activities.

3.4.2 Cleaning surfaces potentially contaminated with nanomaterials should be done with a vacuum cleaner with HEPA filter.

3.4.3 Dry sweeping or compressed air to clean areas with nanomaterials is not recommended.

3.5 Medical surveillance

3.5.1 Medical surveillance of all people potentially exposed to nanomaterials should be undertaken. 3.5.2 Medical surveillance should pay special attention to pulmonary, liver, kidney and hematopoietic cells function.

3.5.3 Any health problem must be registered in order to allow early detection on nanomaterials impacts.

3.5.4 Manipulation of nanomaterials by pregnant women is contraindicated.

3.6 Transport

3.6.1 Nanomaterials should be carried and treated as chemical products, meaning in sealed and labeled containers.

3.6.2 Depending on the transport way specific regulation must be observed.

3.7. Destination /disposal

3.7.1 Nanomaterial with low water solubility (more than a milligram range) should be treated as chemical waste.

3.7.2 Nanomaterial with high solubility in water should be treated the same as macroscopic materials toxicity class.

3.7.3 For nanomaterial in solution the same procedures used for solvents should be used.

3.7.4 Among the forms of waste disposal are: incineration, 
chemical treatment and immobilization.

3.7.5 Packaging and contaminated materials must receive the same attention as nanomaterials themselves, observing that they should be considered dangerous and must not be discarded as regular waste.

3.8. Individual protection equipment

3.8.1 Respiratory protection should be adopted and in general, it is recommended disposable masks when handling group I products, half facemasks cartridge type for group II and even breathing apparatus with air sent for the group III or large concentrations. Regardless of the general recommendations above activities involving nanoparticles should be a specific program for respiratory protection target.

3.8.2 Gloves must be used in order to avoid contact with nanoparticles and the compatibility of the material which it is made of (nitrile, latex, polymer resistant to chemicals, etc.) with the material to be manipulated should be observed. Gloves should overlap the sleeves of the coat and be removed inside the same closed area, for example, in the chapel.

3.8.3 Safety glasses or face shields should be used whenever there is a possibility of material projection. 3.8.4 Closed footwear with low permeability is the most suitable.
3.8.5 Other equipment may include laboratory coats, aprons or coats that should not be made from cotton, wool or mesh. Tyvex, polypropylene or similar material may be adopted.

4. Evaluation

4.1 Monitoring and measuring performance: it is recommended that performance indicators are established regarding to OHS, which can be followed to obtain or infer the results of controls and actions implemented.

4.2 Investigation of injuries, health deterioration, illness and work-related incidents and their impact on OHS performance: the evaluation must strongly interact with medical supervision, documentation and communication systems in order to identify as early as possible any possible deviation or non-compliance with the OHS.

4.3 Audit: internal and external audits should be performed periodically with the ultimate goal of improving the process.

4.4 Management review: the administration is primarily responsible for the OHS performance.

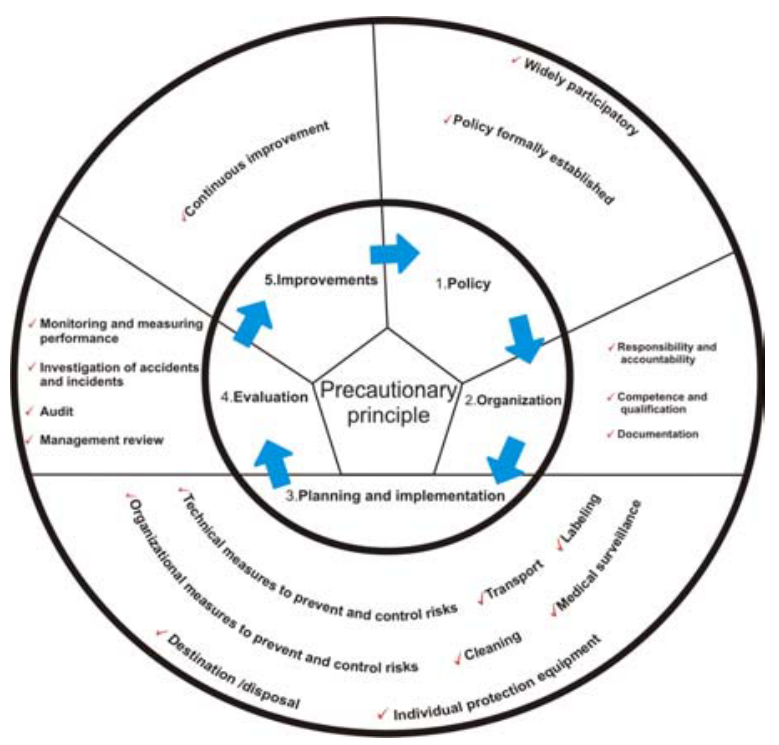

Figure 1

Proposed methodology Diagram 


\begin{tabular}{|c|c|c|c|c|}
\hline $\begin{array}{l}\text { Number } \\
\text { Question }\end{array}$ & Question & $\begin{array}{l}\text { Answer } \\
\text { (Y or N) }\end{array}$ & Action & Result \\
\hline \multirow[t]{2}{*}{1} & \multirow{2}{*}{$\begin{array}{l}\text { Has the material in question different properties } \\
\text { than the same material micro/macroscopic forms? }\end{array}$} & NO & Not treat substance as nano & $\begin{array}{c}\text { IT IS NOT } \\
\text { nanomaterial }\end{array}$ \\
\hline & & YES & Answer question 2 & --- \\
\hline \multirow[b]{2}{*}{2} & \multirow[b]{2}{*}{ Is there a conclusive data on nanomaterials safety? } & NO & Answer question 3 & ---- \\
\hline & & YES & $\begin{array}{l}\text { Observe specific rules for } \\
\text { this nanomaterial and } \\
\text { algorithm end }\end{array}$ & GROUP I \\
\hline \multirow[b]{2}{*}{3} & \multirow{2}{*}{$\begin{array}{l}\text { The nano-objects are fibrous or contain } \\
\text { predominant size? }\end{array}$} & $\mathrm{NO}$ & Answer question 4 & ---- \\
\hline & & YES & $\begin{array}{l}\text { Observe recomendations for } \\
\text { Group III and algorithm end }\end{array}$ & GROUP III \\
\hline \multirow[t]{2}{*}{4} & \multirow[t]{2}{*}{ Containing soluble or labile nanoparticles? } & NO & $\begin{array}{l}\text { Observe recomendations to } \\
\text { Group III and algorithm end }\end{array}$ & GROUP III \\
\hline & & YES & Answer question 5 & ---- \\
\hline \multirow[b]{2}{*}{5} & \multirow{2}{*}{ Frequently using $(*) ?$} & NO & $\begin{array}{l}\text { Observe recomendations to } \\
\text { Group II and algorithm end }\end{array}$ & GROUP II \\
\hline & & YES & $\begin{array}{l}\text { Observe recomendations to } \\
\text { Group III and algorithm end }\end{array}$ & GROUP III \\
\hline
\end{tabular}

(*) Frequent usage: 1 or more times a week; Sporadic or infrequent: once a month

Figure 2

Algorithm proposed for risk group classification (based on Fronza et al. [7])

5. Improvements

5.1 Preventive and corrective actions

5.1.1 Follow-up studies in progress and adjusting the system where it is necessary.

5.2 Continuous improvement

5.2.1 Each system item must be periodically reviewed to ensure that it remains adequate for the purpose.

\section{Discussion and conclusion}

For nanotechnologies the precautionary principle seems to be the most appropriate approach [8]. However, a pragmatic system of risk control that incorporates this principle is needed. A tool for risk management will likely lack of other inputs such as personnel and knowledge management systems [12].

The risks associated to nanoparticles depend on several physical characteristics (size, shape, surface morphology, surface area, surface load, rheology, porosity, crystallinity, etc.) and chemical (composition, surface chemistry, stoichiometry, kinetics of dissolution and solubility, hydrophilicity and hydrophobicity besides the presence of impurities) [7]). All the above analysis bring out particles data, but provide no information about their interaction with human organism nor what they are and how the processes of dermal absorption, inhalation, ingestion or eye contact work.

The discussion above concludes the importance to believe on the risk and act on the uncertainty as precautionary principle advocates. Although literature reports evidence of risks in handling nanomaterials $[6,7,8,9,10,11,12,13,14,15,16,17]$ only about $10 \%$ of researchers who work with nanomaterials wear nanoenabled hoods for example. Moreover, one in four researchers do not adopt any kind of collective protection for the laboratory [4]. In this context, Balas and colleagues [4] suggest that scientific magazines should start demanding detailed description of care and safety actions related to handling nanomaterials in order to force the adoption of these measures by 
researchers/authors.

Despite the likely non-acceptance of this suggestion, seems obvious to say that the concern in dealing with nanomaterials is legitimate and worrisome, given that researchers are the first to have contact with potentially hazardous new substances.

Gaps in knowledge about the effects of nanomaterials on humans and environment open up important opportunities in areas as diverse as the techniques of engineering and occupational hygiene, reaching ethical and legal issues regarding access to information, for example.

\section{References}

[1] Araújo, G. M. de (2008). Sistema de Gestão de Segurança e Saúde Ocupacional OHSAS 18.001/2007 and ISM Code Comented, $1^{\mathrm{a}}$ ed., Gerenciamento Verde Editora, Rio de Janeiro.

[2] Araújo, G. M. de (2008). Sistema de Gestão de Segurança e Saúde Ocupacional OHSAS 18.001/2007 and OIT SSO/2001, $2^{\text {a }}$ Edição, vol 2, Gerenciamento Verde Editora, Rio de Janeiro.

[3] Balas, F., Arruebo, M., Urrutia, J., Santamaria, J. (2010). Reported nanosafety practices in research laboratories worldwide, Nature Natotechnology, vol 5, 93-96.

[4] Barreiros, D. and Richers, R. S. (2005). Fatores organizacionais críticos como parâmetros para conceber, implementar e manter um sistema de gestão de segurança e saúde no trabalho, dissertação mestrado SENAC/SP, São Paulo.

[5] Dupont and Environmental Defense, (2007). Nano Risk Framework.

[6] Ellenbecker, M., Tsai, S., (2008). Interim Best Practices for Working with Nanoparticles. Center for High-Rate Nanomanufacturing, Revision 1.

[7] Fronza, T., Guterres, S.. Pohlmann, A., Teixeira, H. (2007). Nanocosméticos em direção ao estabelecimento de marcos regulatórios. Gráfica da UFRGS, Porto Alegre, Brazil.

[8] Hallock, M., Greenley, P., Diberardinis, L., and Kallin, D. (2009). Potential risks of nanomaterials and how to safely handle materials of uncertain toxicity, Journal of Chemical Health and Safety 16, 16-23

[9] ILO (International Labour Organization) (2001). Guidelines on Occupational Safety and Health Management Systems - ILOOHS 2001. Tradução de Gilmar da Cunha Trivelato, Diretrizes sobre Sistemas de Gestão da Segurança e Saúde no Trabalho. São Paulo: FUNDACENTRO, 2005.

[10] Marchant, G. E., Sylvester, D. J., Abbott, K. W. (2008). Risk Management Principles for Nanotechnology, NanoEthics 2, 43-60.

[11] MIT, (2011), University Best Practice. http://ehs.mit.edu/site/sites/default/files/University_Best_Pract ices.pdf, (Apr. 7, 2011).

[12] Ostiguy, C., Roberge, B., Ménard, L., Endo, C. (2009). Best practices guide to synthetic nanoparticle risk management Report R-599, Institut de recherche Robert-Sauvé en santé et en sécurité du travail (IRSST), Québec, Canada.
[13] State Secretariat for Economic Affairs (SECO) (2010). Safety data sheet (SDS) Guideline for synthetic nanomaterials, Swiss.

[14] Texas A\&M Engineering. Interim Guideline for Working Safely with Nanotechnology. http://engineering.tamu.edu/safety/guidelines/Nanotechnology/ NANO_SafeGuideline.pdf (Apr. 7, 2011).

[15] US/DOE (2008). Approach to Nanomaterial ES\&H, revision 3a.http://www.sc.doe.gov/bes/doe nsre approach to nanomaterial_esh.pdf (Apr. 7, 2011).

[16] US/DOE/Stanford Linear Accelerator Center, (2008). Nanomaterial Safety Plan 4.

[17] US/NIOSH (2009). Approaches to Safe Nanotechnology. 